\title{
The Impact of Demand and Cost Factors on Inflation in Open Economies
}

\section{Introduction}

Bruno [1] develops a theoretical model of the wage-price adjustment process in an open economy to consider the dynamic impact of changes in import prices and exchange rates. In his model nominal wages are a function of the excess demand for labor, import prices $\left(P_{m}\right)$ and an adaptive expectation term which is measured by a lag of the consumer price index $\left(P_{c-1}\right)$. The consumer price index $\left(P_{c}\right)$ is a function of these three variables and the excess demand for home goods. Bruno finds that most of the variation of inflation rates for 16 OECD countries for 1972-76 is explained by the initial cost-push effect of the growth of import prices and the expectation of domestic inflation. This conclusion is based upon the empirical results obtained from estimating the pooled 64 cross-section and time series observations of a naive version of his model shown in equation (1).'

$$
\dot{P}=\underset{(0.92)}{3.12}+\underset{(0.074)}{0.517} \dot{P}_{c-1}+\underset{(0.021)}{0.177} \dot{P}_{m} \quad R^{2}=.811
$$

A dotted variable indicates the rate of change in that variable and standard errors are shown in parentheses. In this model Bruno assumes zero excess demand in both the domestic goods and labor markets and obtains significant and positive coefficients for the inflationary expectations and import price variables.

However in Bruno's theoretical development, demand conditions in both the product and labor markets are important determinants of inflation in open economies. Furthermore, it seems probable that the delayed impact of domestic policy demand variables must be included in the model to consider their impact on domestic rates of inflation and their effectiveness in dampening inflationary pressures. In this paper we test Bruno's theoretical model by dropping the assumption of zero excess demand in the product and labor markets. Variables are specified for the relative impact of import prices, the tightness of the labor market, and of various demand variables upon domestic inflation. Our variation of Bruno's model is developed in Section II. Individual time-series results are presented for thirteen of Bruno's sixteen countries for which sufficient quarterly data was available for testing. Empirical results are presented in Section III for the period of predominantly fixed exchange rates which

1. Comparable coefficients on import prices and lagged domestic prices are found with our data for the 197276 and the 1969-76 time perids. 
ended in the first quarter of 1973 and for the extended period of fixed and floating exchange rates. Therefore, our empirical results suggest possible differences between countries and exchange-rate regimes. Final remarks follow in Section IV.

\section{The Model}

Home prices $\left(P_{h}\right)$ are hypothesized to depend upon nominal wages $(W)$, import prices in domestic currency $\left(P_{m}\right)$, the expected rate of inflation $\left(\Pi_{h}\right)$, and the demand for home goods expressed by a vector of exogenous policy variables $(d)$,

$$
\dot{P}_{h}=a_{1} W+a_{2} \dot{P}_{m}+a_{3} \dot{\Pi}_{h}+f(d)
$$

where $a=a_{1}+a_{2}+a_{3} \leq 1$ and $f^{\prime}>0$. For estimation purposes it is convenient to consider the rate of change of the consumer price index $\left(\boldsymbol{P}_{\mathrm{r}}\right)$ which includes both imported and home products with weights of $\mu$ and $(1-\mu)$ respectively,

$$
P_{c}=(1-\mu) \dot{P}_{h}+\mu \dot{P}_{m}=\alpha_{1} W+\alpha_{2} \dot{P}_{m}+\alpha_{3} \dot{\Pi}_{h}+(1-\mu) f(\dot{d})
$$

where $\alpha_{1}=(1-\mu) a_{1}, \alpha_{2}=\left[(1-\mu) a_{2}+\mu\right], \alpha_{3}=(1-\mu) a_{3}, \alpha=\alpha_{1}+\alpha_{2}+\alpha_{3}=(1-\mu)\left(a_{1}+a_{2}+\right.$ $\left.a_{3}\right)+\mu \leq 1$.

For simplicity the expectations term is assumed to be determined in a similar manner,

$$
\grave{\Pi}_{c}=(1-\mu) \Pi_{h}+\mu \dot{P}_{m} .
$$

The nominal wage rate $(W)$ is assumed to be an endogenous variable which is determined by a Phillips curve equation:

$$
W=b \dot{\Pi}_{c}+\phi(l)
$$

where $\phi(l)$ reflects excess demand in the labor market such that $\phi(0)=0$ and $\phi^{\prime}>0$. Labor market conditions, $\phi(l)$, are specified as $(V / U)$, the ratio of job vacancies to unemployment. ${ }^{2}$ Upon substitution, equation (5) becomes

$$
W=b_{1} \dot{\Pi}_{h}+b_{2} \dot{P}_{m}+b_{3}(V / U)
$$

where $b_{1}=b(1-\mu), b_{2}=b_{\mu}$ and $b_{1}+b_{2} \leq 1$.

Substitution of equation (6) into (3) yields equation (7) which relates the rate of change in the consumer price index $\left(P_{c}\right)$ to expected inflation $\left(\Pi_{h}\right)$, the rate of inflation in imported goods $\left(\dot{P}_{m}\right)$, labor market conditions $(V / U)$, and the rate of growth of demand in the product market, $f(\dot{d})$ :

$$
P_{c}=c_{1} \Pi_{h}+c_{2} P_{m}+c_{3}(V / U)+(1-\mu) f(d)
$$

where $c_{1}=\left(\alpha_{1} b_{1}+\alpha_{3}\right), c_{2}=\left(\alpha_{1} b_{2}+\alpha_{2}\right), c_{3}=\alpha_{1} b_{3}$ and $c_{1}+c_{2}+c_{3} \leq 1$.

Bruno's assumption that expected inflation is simply equal to the rate of infiation in the previous period is altered to allow the expected rate of change in home prices to be a function of the growth rates of demand variables in the previous $n$ periods. This means that price adjustments due to changes in import prices are known when inflationary expectations are formed. Therefore, equation (7) can be rewritten

2. Holt $[2,345]$ uses $(V / U)$ as an important explanatory variable in a Phillips curve wage equation. 


$$
P_{c}=c_{1} f\left(d_{t-1}, d_{1-2}, \ldots, d_{t-n}\right)+c_{2} P_{m}+c_{3}(V / U)+(1-\mu) f(d) .
$$

For econometric purposes, equation (8) can be rewritten as

$$
\begin{aligned}
\dot{P}_{c}=\alpha & +\xi \dot{P}_{m}+\theta(V / U)+\sum_{i=0}^{n} \beta_{i} \dot{B}_{t-1}+\sum_{i=0}^{n} \gamma_{i} \dot{E}_{t-1}+\sum_{i=0}^{n} \delta_{i} T_{t-1} \\
& +\sum_{i=0}^{n} \psi_{i} E x_{t-1}+\epsilon_{t .}
\end{aligned}
$$

The vector of demand variables includes a monetary policy variable defined as either the monetary base $(B)$ or the money supply $(M)$, real government expenditures $(E)$, real $\operatorname{tax}$ recepits $(T)$, and real exports $(E x)$.

The appropriate distributed lag for each of the three domestic policy variables is determined by searching over a twelve period distributed lag (current period plus eleven lag periods) and minimizing the standard error of the regression. ${ }^{3}$ If the last coefficient of the lag is significant and the correct sign, an F-test is conducted to examine the null hypothesis that the whole group of lagged coefficients is equal to zero. A failure to reject the null hypothesis at the five percent level of significance results in a reduction of the length of the lag until a significant coefficient of the correct sign is reached. A rejection of the null hypothesis means that the sum of the lagged coefficients are significantly different from zero and the length of the lag is accepted. By this procedure any insignificant coefficients at the end of a distributed lag can be eliminated to save degrees of freedom unless the whole group of coefficients is significantly different from zero. ${ }^{4}$

\section{Empirical Results}

Equation (9) is estimated for the period of fixed exchange rates through the first quarter of 1973 and for the period of fixed and floating exchange rates through 1978. ${ }^{5}$ The results for the fixed-exchange-rate period are presented in Table I for the monetary base equation and in Table II for the money supply equation. Bruno's result that there is a significant impact upon domestic inflation from the rate of change of import prices for 1972-76 is not substantiated for all thirteen countries for the period of fixed exchange rates. The import price coefficient is positive and significant in both the monetary base and money supply equations for Belgium, Ireland, Japan and Norway and in only the monetary base equation for Italy and the Netherlands. Therefore, domestic inflation rates in seven of the countries were not significantly influenced by a direct price effect from abroad prior to the breakdown of the Bretton Woods fixed-exchange-rate system.

3. However, there is no guarantee that the "best" lagged structuere has been found, because a search over a maximum of fifteen or nineteen lagged periods might produce different results.

4. Equation (9) is modified by dummy variables for several countries to designate significant data splices. Seasonal dummy variables where $S 1, S 2$ and $S 3$ equal the first, second and third quarters were tested for each equation for each country and are included if the set of coefficients are significantly different then zero.

5. The data was obtained from various issues of the International Monetary Fund's International Financial Sratistics and OECD's Main Economic Indicators. Missing quarterly data for expenditures and taxes for Sweden and Switzerland were interpolated from annual data. Quarterly Swiss monetary base and moncy supply figures are based upon February, May, August and November observations. Insuficient quarterly data was available for Canada, Australia and Denmark to include these countries in the study. 


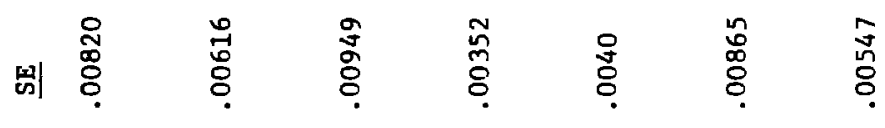

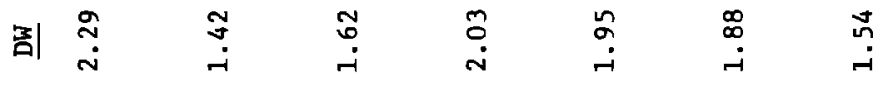

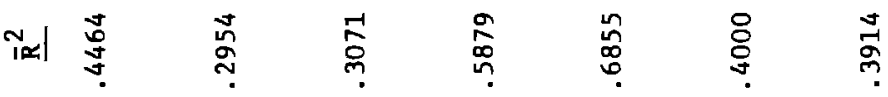

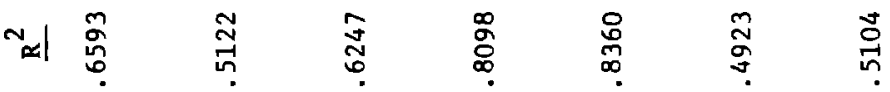

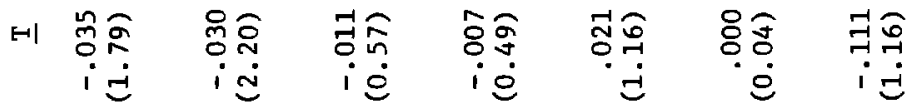

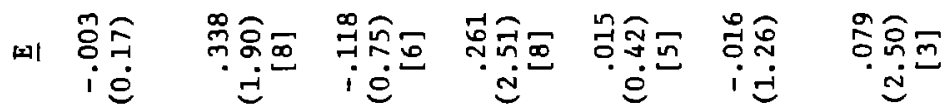

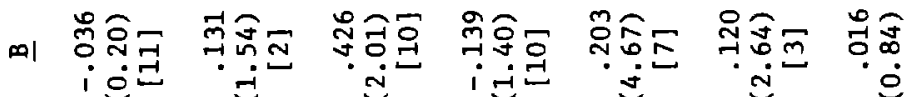

管疋

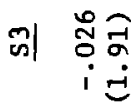

ํํㅇ

iอ

w

ถัด

i

히 ํㅗㅇํㅇ

范

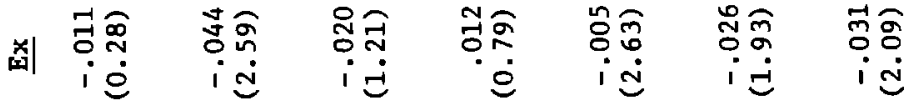

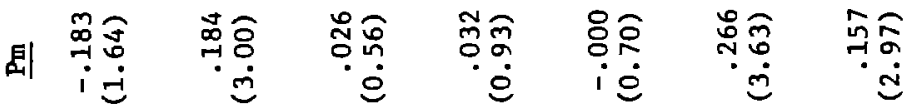

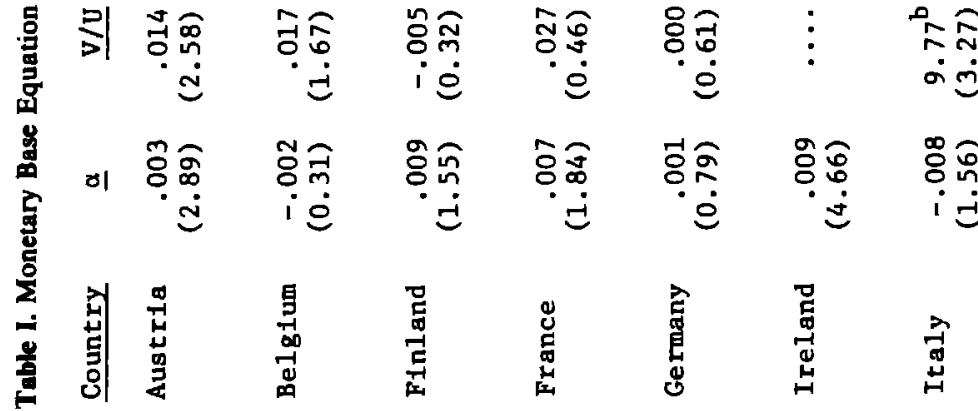




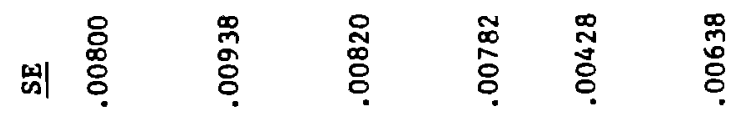

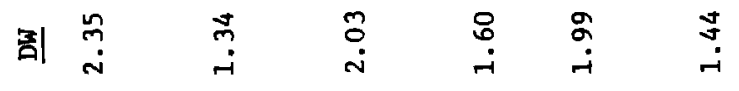

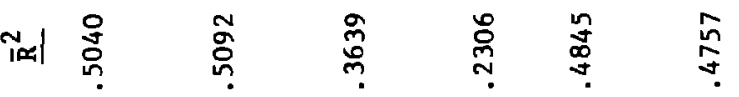

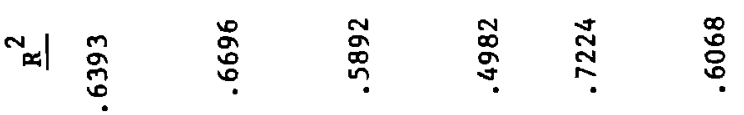

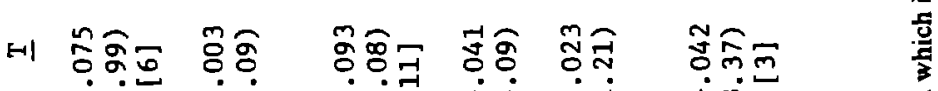

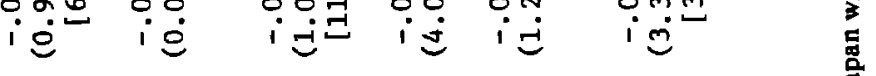

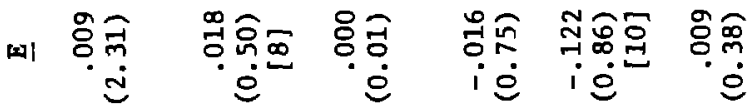

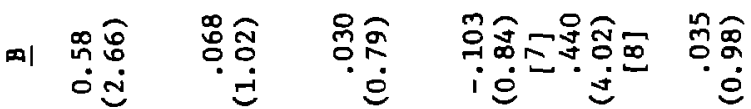

DI

की

ผุกิ

क⿻ $\quad$ कo

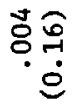

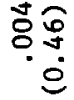

ํํำ

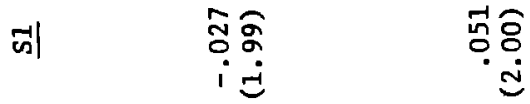

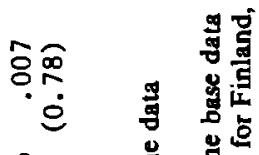

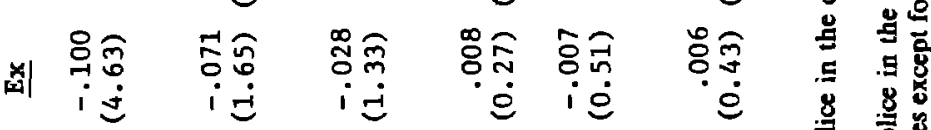

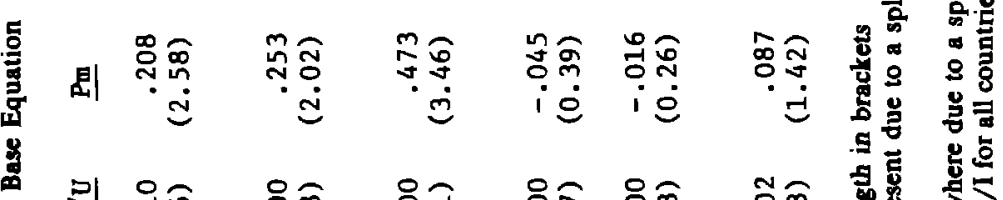

쾩 웡 员

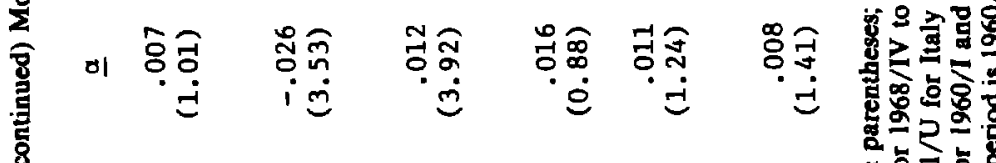

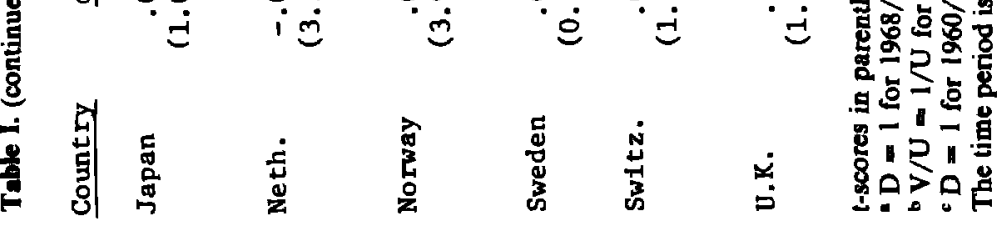




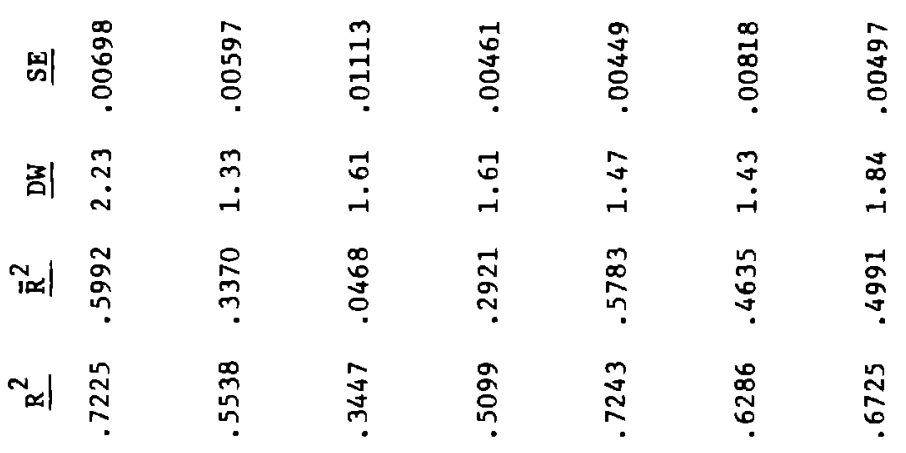

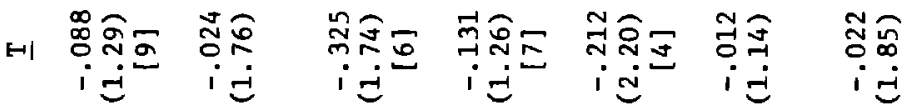

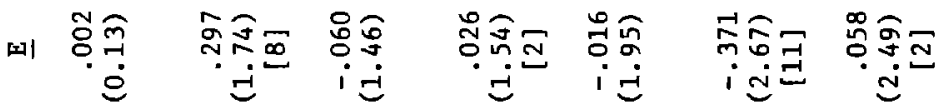

₹

D)

ต็ สิ

का

ีำ

$i$ ¿ป

क)

영.

히

สิ่

iป

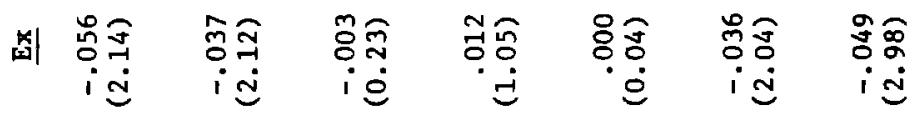

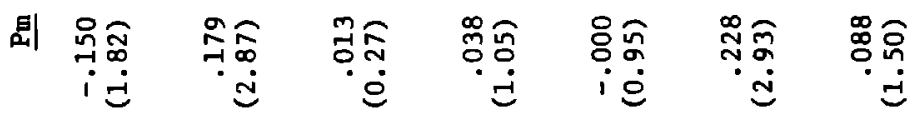

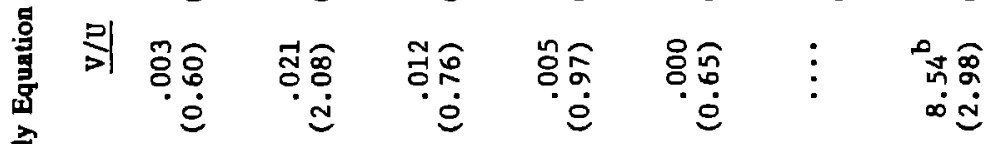

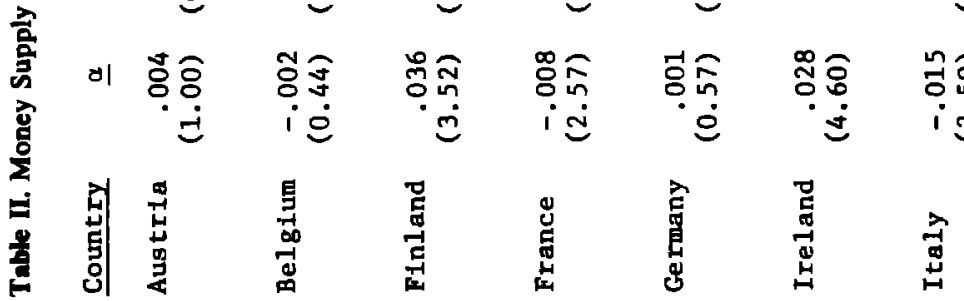




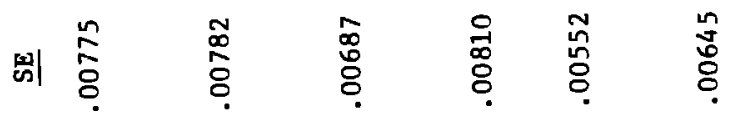

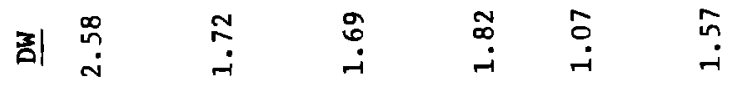

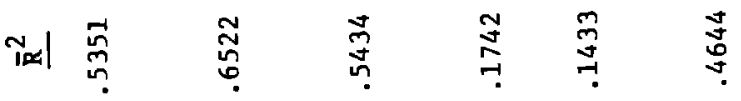

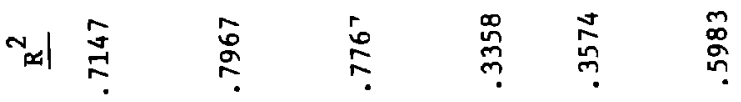

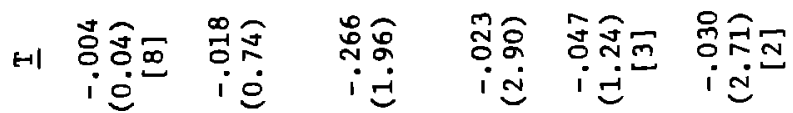

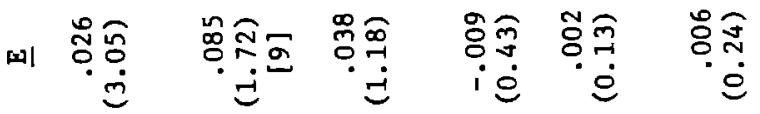

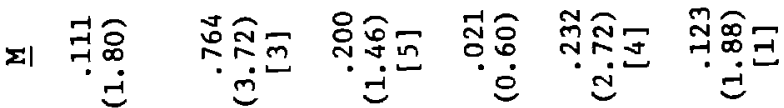

al

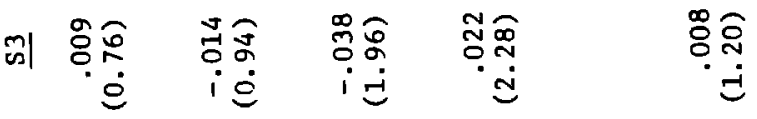

๗)

का 矛高第

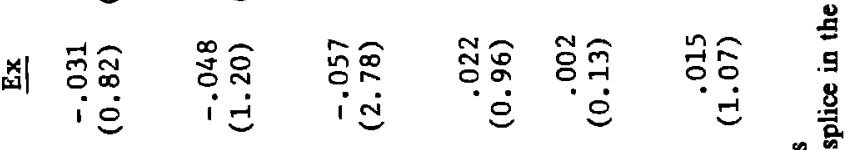

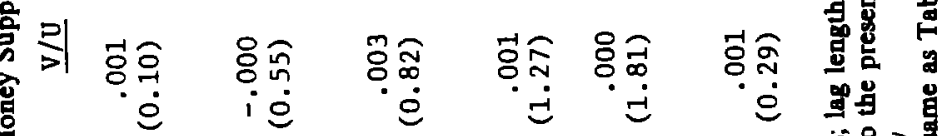

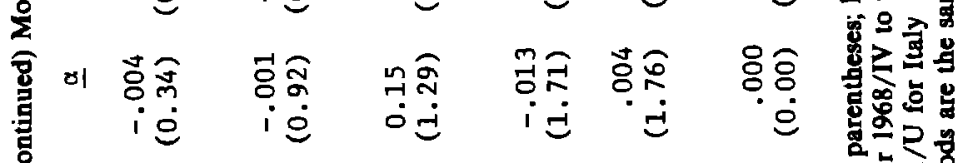

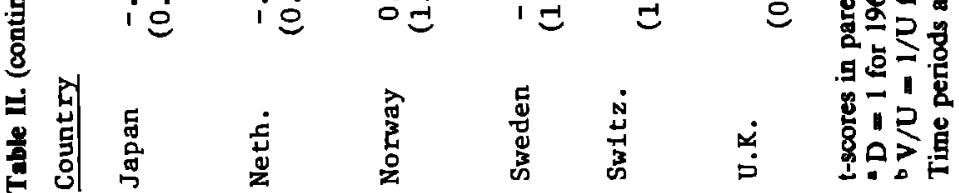


The result of estimating equation (9) for the extended period of $1960 / \mathrm{I}-1978 / \mathrm{IV}$ for the monetary base and the money supply are presented in Tables III and IV respectively. The import price coefficient is positive and significant in both equations for eight of the thirteen countries. The significant coefficients range in size from .071 to .238 . Furthermore, three of the four countries for which the import price coefficients are insignificant for both equations are countries with appreciating currencies: Austria, Germany and Switzerland. The exception is the United Kingdom whose import price coefficient is insignificient for both equations. Therefore, the quarterly time-series results which include the period of floating exchange rates and the oil cartel show that import prices were a contributing factor to the domestic rates of inflation for eight of the countries. However, the evidence does pinpoint four countries for which import prices did not directly affect domestic inflation.

The empirical results also show that other variables are significantly related to the domestic rates of inflation. The growth rate of the monetary variable has a positive and significant impact upon inflation for Finland, Germany, Ireland, Japan and Switzerland for the monetary base equation and for Austria, Germany, Italy, the Netherlands and Switzerland for the money supply equation over the period of fixed exchange rates. However, only Switzerland and Germany have a positive and significant coefficient for both the monetary base and money supply equations. Estimates for the extended period show that the sum of the monetary base coefficients are significant for nine of the thirteen countries with $t$-scores ranging from 2.8 to 6.4 . The sizes of the $t$-scores for these nine countries over the extended period suggest that the abandonment of the fixed-exchange-rate system in 1973 did enable monetary authorities in open economies to use the monetary base as a policy variable to influence the domestic rate of inflation. The money supply equation confirms the importance of monetary policy for seven of the thirteen countries.

Fiscal policy also proved to be significantly related to the domestic inflation rate for both time periods in various countries. The sum of the government expenditure coefficients are positive and significant for Belgium, France, Italy and Japan for the monetary base equation and for Belgium, Italy and Japan for the money supply equation for the fixed-exchange-rate period. For the extended period, the sum of the government expenditures coefficients are positive and significant with increased size in the t-score for Belgium, France, Germany and Norway for the monetary base equation and for Belgium, France and Switzerland for the money supply equation. The sum of the tax receipts coefficients tends to be very close to zero even in those cases where the coefficients are negative and significant. The main exceptions are Germany and Ireland, which have strongly negative and significant coefficients for tax receipts in at least two of the equations.

The other variables did not have coefficients which were consistently significant with the right sign. The real export variable is never positive and significant. There is no obvious reason why the coefficients are often negative and significant. The coefficient for the ratio of vacancies to unemployment also does not perform in any systematic manner. These results suggest that alternative specifications of external demand pressures and internal labor market pressures might be desirable in future studies.

\section{Conclusion}

Bruno's theoretical model of inflation for open economies relates domestic inflation to the rate of change in import prices, inflationary expectations, the rate of change of nominal 


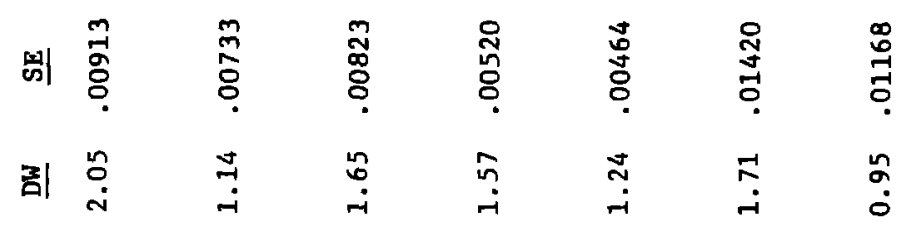

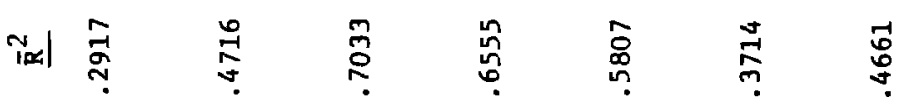

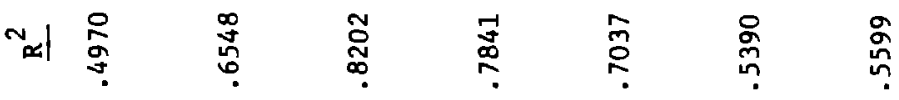

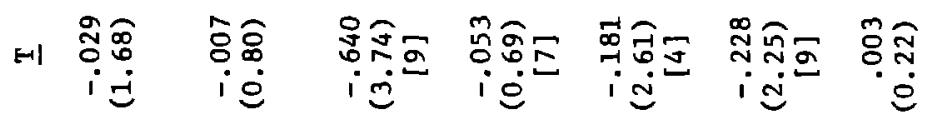

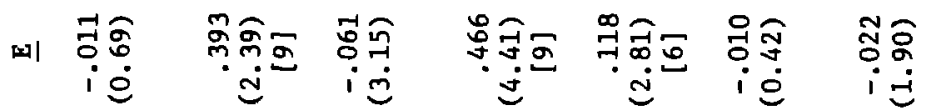

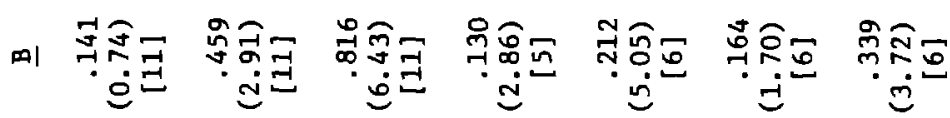

al

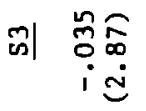

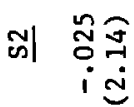

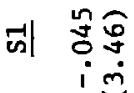

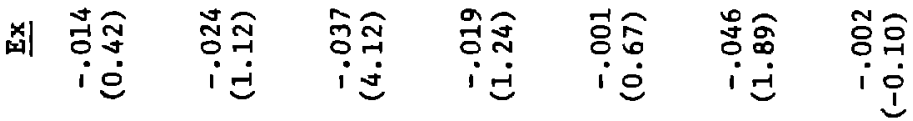

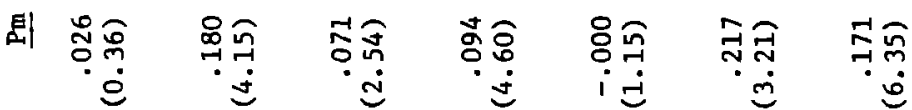

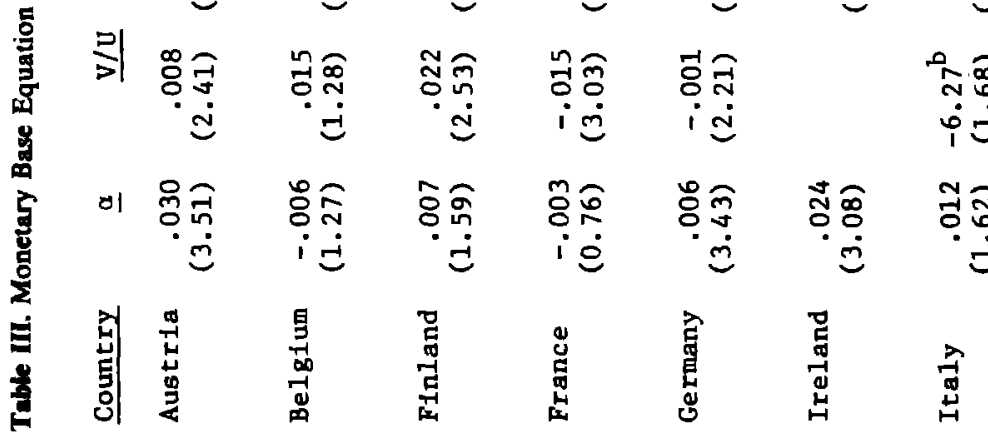




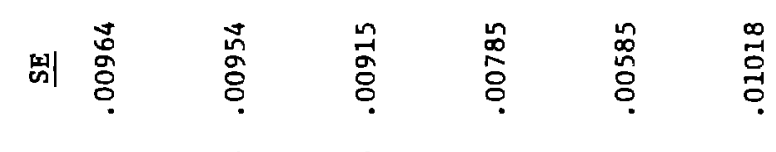

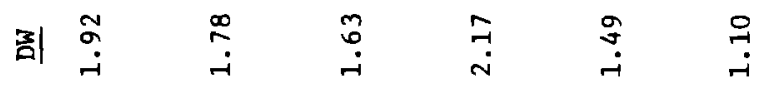

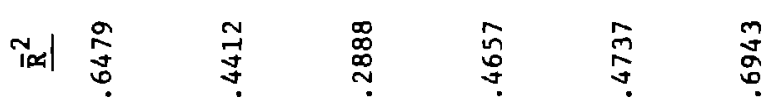

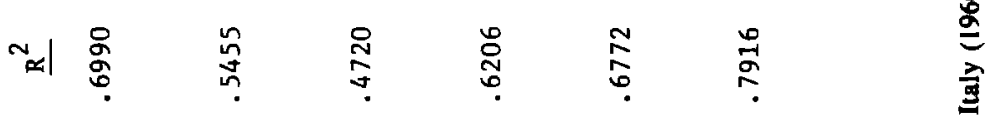

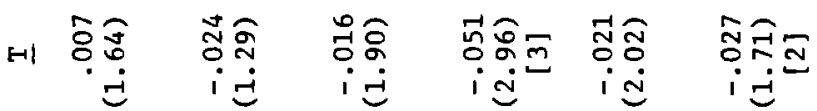

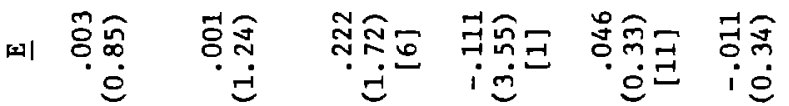

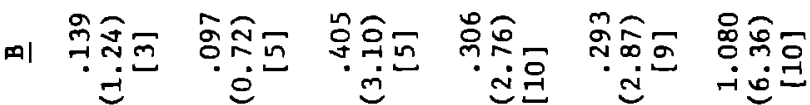

Al

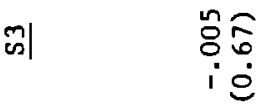

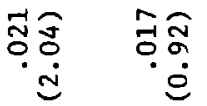

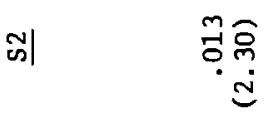

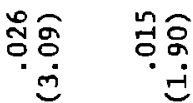

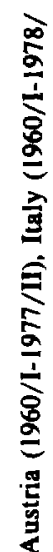

जा

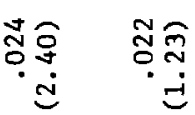

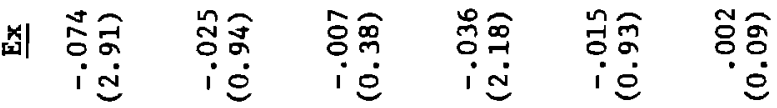

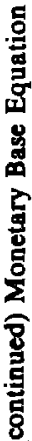

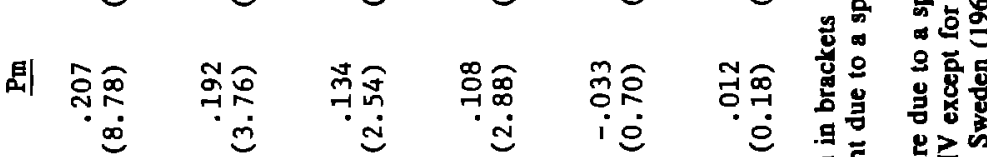

귁 응 ธิ์ i.j $\quad$ id

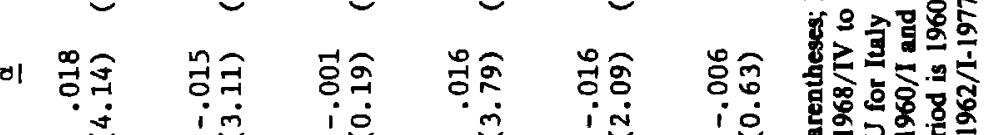
ن i⿺ id

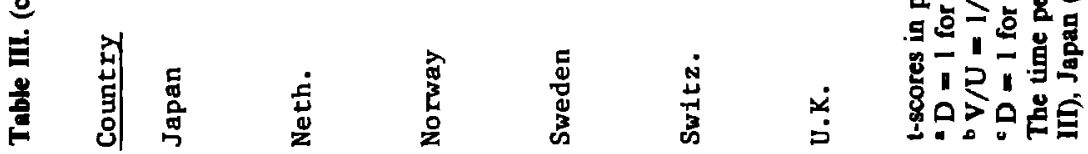




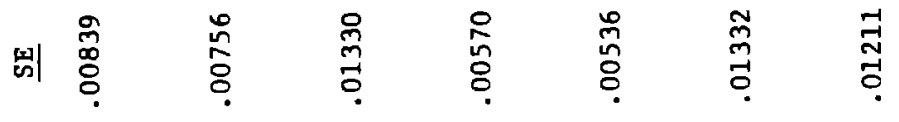

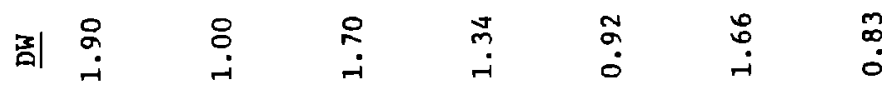

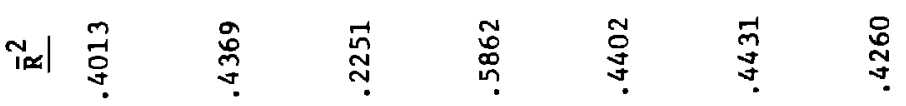

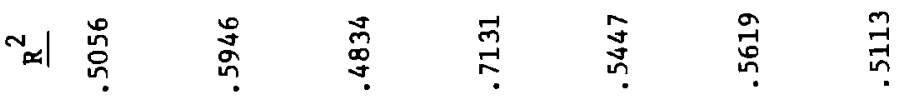

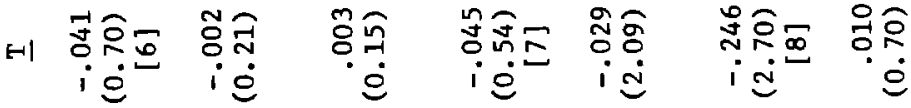

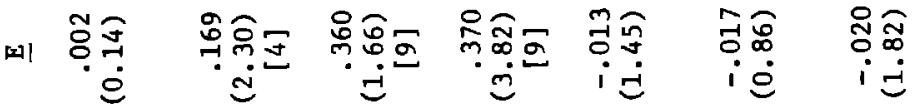

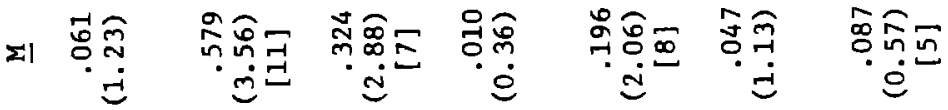

al

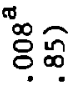

के)

ำำ

ธีเ

홍요

$\dot{0}$

ज़|

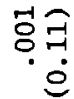

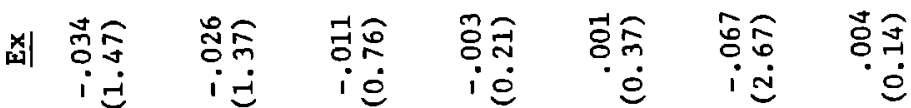

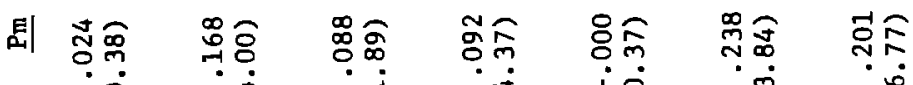

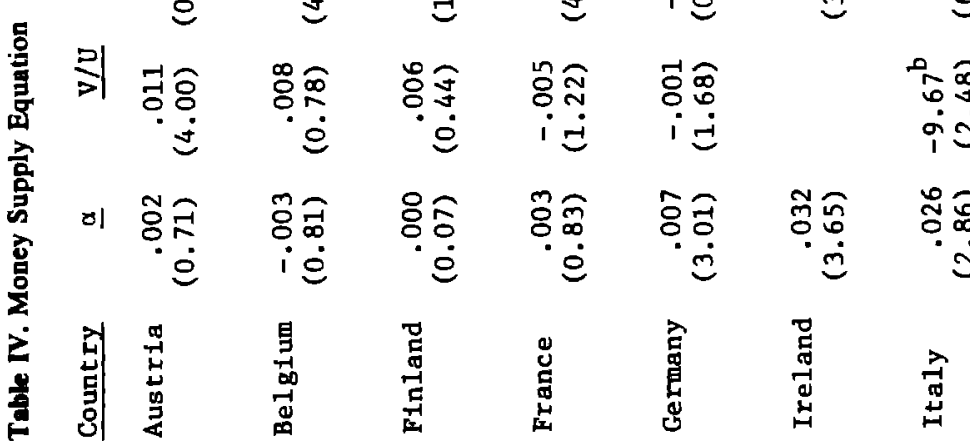




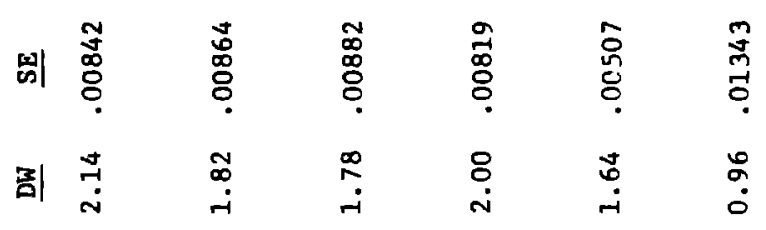

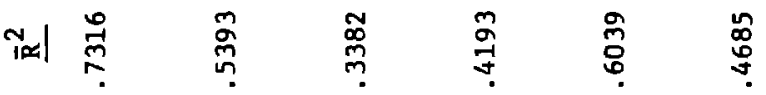

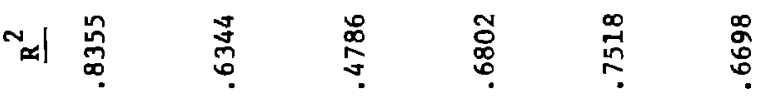

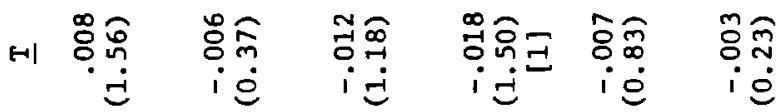

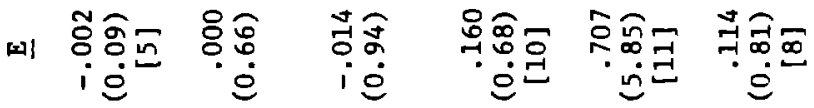

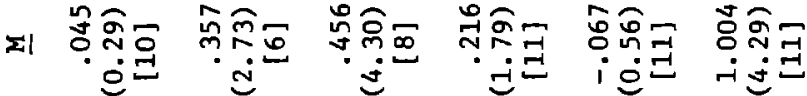

๑)

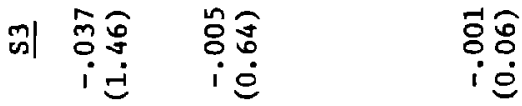

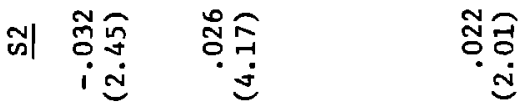

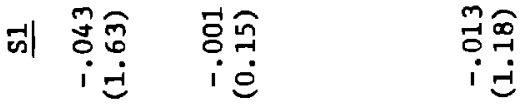

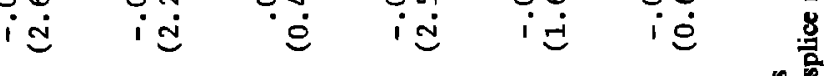

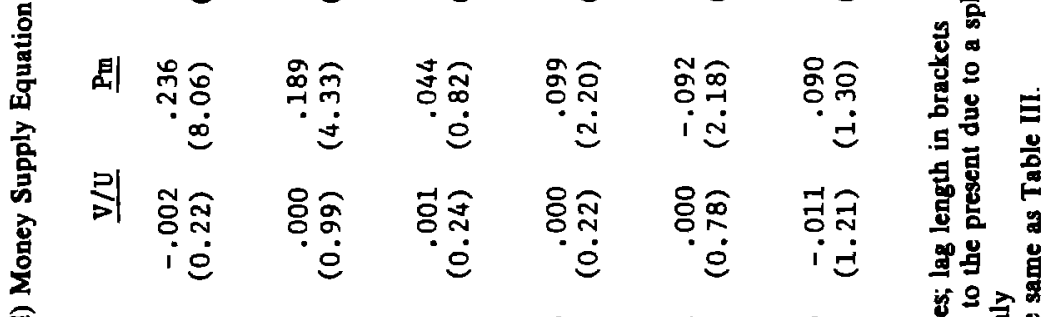

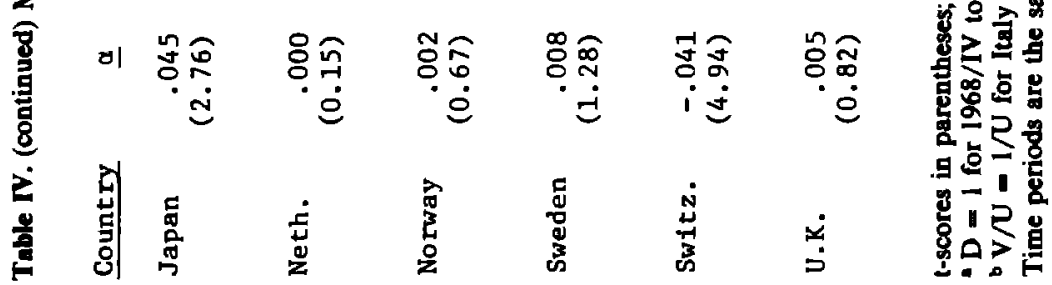


wages and the excess demand for home goods. However, Bruno's empirical results are based solely upon import prices and a expectations term. We extend Bruno's empirical analysis by dropping the assumption of zero excess demand in the good and labor markets. Additionally, we model price expectations not by a lagged inflation variable but by the lag of domestic demand variables. Our results for the fixed-exchange-rate period show that import prices do not have a significant impact upon domestic inflation rates for all thirteen countries. Furthermore, domestic demand variables often contribute to inflationary pressures. For the extended period which includes floating exchange rates, the impact from import price and domestic policy variables were often stronger than for the fixed-rate period. At least one of the domestic policy variables has a significant impact upon domestic inflation in each country except Austria and Japan. However, it would take specific investigation of each country to determine whether domestic policies continued to increase or to restrain the domestic inflation rate.

Stuart D. Allen

Donald L. McCrickard

University of North Carolina at Greensboro Greensboro, North Carolina

\section{References}

1. Bruno, Michael, "Exchange Rates, Important Costs, and Wage-Price Dynamics." Journal of Political Economy, June 1978, 379-403.

2. Holl, Charles C., "Labor Market Structure: Implications for Micro Policy." American Economic Review, May 1978, 342-47. 